\title{
Sobre la transmisión de la tuberculosis y los primeros ensayos del BCG
}

\author{
ENRIQUE LAVAL R.
}

\section{About Tuberculosis transmission and the first BCG vaccine assays}

Es posible que la tuberculosis la hayan padecido los animales, milenios antes de la aparición del hombre sobre la tierra.

Alrededor de 5.000 años a.C. se encontraron lesiones de las vértebras cervicales en el esqueleto de un joven, atribuidas a la tuberculosis. En la India se comprobó la enfermedad 1.000 años a.C. y los médicos griegos y romanos, ya conocían la tuberculosis pulmonar (fiebre héctica). En América la enfermedad estuvo presente precediendo al arribo de los conquistadores, como lo atestiguan lesiones pulmonares y óseas encontradas en momias. Sin embargo, con la llegada de aquellos, se produjo rápidamente su propagación entre los aborígenes, matando en muchas regiones a casi toda la población nativa, como aconteció en la Patagonia y Tierra del Fuego.

Esta enfermedad "tan temida, mal interpretada y de tratamiento insatisfactorio, que no distinguía estados sociales, rangos o actividades", tendría en la segunda mitad del siglo XIX, importantes hitos, que finalmente conducirían a medidas de prevención y terapias eficaces. ${ }^{2}$

En 1865, Villemin, había demostrado la inoculabilidad de la tuberculosis en los animales. El 24 de marzo de 1882, Roberto Koch anunciaba el descubrimiento del bacilo de la tuberculosis: "sabemos -decía- que este parásito no encuentra sus condiciones de existencia, sino en el cuerpo del hombre y de los animales y que no puede desarrollarse, como el bacilo del carbón, en el medio ambiente: es ésta una adquisición muy consoladora desde el punto de vista de la lucha contra la tuberculosis y de ello deriva que es preciso dedicarse, ante todo, a segar las fuentes de donde proviene la infección. Una de ellas y ciertamente la principal, es la expectoración de los tísicos, que es necesario desinfectar y tomarla inofensiva".

En el $10^{\circ}$ Congreso Internacional de Medicina, realizado en Berlín en 1890, Roberto Koch terminó su exposición expresando que: "en la batalla por el bienestar de toda la humanidad una nación puede aventajar siempre a la otra en sus éxitos"'.

A pesar de todo esto, aún en 1882, los médicos se dividían en partidarios y adversarios de la transmisibilidad de la enfermedad.

En Chile habían ocurrido hechos que incuestionablemente eran extraordinarios: en 1765, el Procurador de la ciudad de Santiago, don Juan de Santa Cruz y Silva, se presentó ante la Real Audiencia para manifestar que pocos años a esta parte se había difundido extraordinariamente la tuberculosis, solicitando se ordenase aplicar medidas que se opusieran a su propagación. La Audiencia refirió su estudio a una Comisión presidida por el Corregidor don Luis Manuel de Zañartu, e integrada por el protomédico doctor don Domingo Nevin, y los médicos don Ignacio de Jesús Zambrano, Fray Matías Verdugo, don Eugenio Núñez y don Cipriano Mesías, dictaminando que: "la enfermedad héctica no es nueva en ella (en la ciudad) porque siempre se ha padecido y padecerán mientras no se curaren con acierto y a raíz los catarros, pulmonías, puntadas, reumas, empachos arraigados, supresión de evacuaciones críticas (de hombres y mujeres y otras semejantes: que no dudan no obstante de ser tantas las causas de que se origina, que se ha extendido en este vecindario por los vapores y hálitos que salen de la pieza en que está el enfermo, de la cama, ropa y demás cosas que sirvan para su curación y uso" y que "les parecía conveniente que se nombre por médico de ciudad al doctor, don Juan Álvarez y que todo el que curare enfermo de este accidente héctico y formase juicio de que lo es, de parte a dicho Doctor Don Juan.

A continuación la citada comisión indicaba realizar una especie de "encuesta epidemiológica" muy minuciosa, además de medidas de "desinfección concurrente y terminal" de acuerdo al pensamiento de la época, finalizando con que "todo lo demás que ha servido a la enfermedad se queme en los extramuros de la ciudad y las vasijas de plata para que se purifiquen al fuego, sin ocultar lo más mínimo, bajo las penas y apercibimientos que se tuvieren por bastantes"5.

\section{¿Podría considerarse al doctor don Juan Álvarez. como el primer Jefe del Programa de Control de la Tuberculosis en Chile?}

Todo esto parecería hoy candoroso y pueril, pero en su época poseía una insospechada dimensión. Basta recordar que el doctor Guillermo Cullen, primer médico del Rey de Inglaterra en Escocia, uno de los más famosos de Europa, expresaba en 1789, en sus "Elementos de Medicina Práctica", obra muy difundida en España y América, que: "los médicos han supuesto frecuentemente que la tisis era una enfermedad contagiosa: no me atrevo a asegurar que nunca lo sea; pero sobre muchos centenares de ejemplos de esta enfermedad que he visto, apenas habrá habido uno de ellos en que la tisis me haya parecido producida por el contagio".

El doctor Jorge Hércules Petit, francés y radicado 
definitivamente en Chile a partir de 1853, fue nombrado profesor de Clínica Médica en 1861. Ese mismo año presentó al certamen abierto anual de la Facultad de Medicina, su trabajo "Investigación de las causas que tan frecuente han hecho en Chile, en los últimos años, la tisis pulmonar e indicación de las medidas preventivas que convendría emplear para removerlas". Con especial énfasis sostuvo que la tuberculosis era un enfermedad contagiosa, pero la comisión designada para calificar la tesis, formada por los profesores Miquel, Tocornal y Elguero, la repudió con energía "por cuanto su autor en su afán de dar alas a la fantasía no había considerado la experiencia de los médicos en el país y las observaciones severamente realizadas en otros. Ha querido asemejar tanto el germen tuberculoso al venéreo, que lo hace aparecer como un virus que puede ser transmisible e inoculable, tal como lo es el de la vacuna, hidrofobia, etc"6.

Como lo hemos señalado, cuatro años más tarde Villemin demostraba la inoculabilidad de la tuberculosis.

Al cumplirse 50 años del feliz e importante descubrimiento de Roberto Koch, en 1932, Alberto Calmette en la Academia de Medicina de Francia dijo: "desde que Roberto Koch sucumbiera bruscamente el 27 de mayo de 1910, a una afección cardíaca, el tiempo ha transcurrido. Ha cumplido su obra. Poco a poco el velo se ha desgarrado, el horizonte iluminado y podemos esperar que las generaciones venideras no conocerán ya este flagelo que es la tuberculosis para todos los pueblos civilizados".

¿Por qué hablaba así Calmette? En 1901, junto con Guerin practicaban experiencias sobre absorción intestinal de los bacilos tuberculosos, haciendo ingerir a vacunos jóvenes, bacilos sembrados en papas biliadas con bilis de buey, facilitando la infección de los animales. Después de una treintena de pasajes sucesivos sobre tales papas, comprobaron con sorpresa que un cultivo de origen bovino, muy virulento, no mataba al cuy. Después de 60 traspasos se encontró el bacilo totalmente avirulento. Las terneras jóvenes inoculadas con este bacilo adquirían una resistencia clara, incontrovertible, a la tuberculosis natural o experimental. Así, este bacilo de Calmette y Guerin (BCG) se comportaba como una vacuna, no pudiendo hacerle recuperar su virulencia original por ningún método.

El 10 de julio de 1921, el doctor Weill-Ilallé, del Hospital de la Charité, comunicó a Calmette un hecho que le preocupaba: un niño recién nacido de una madre tuberculosa, recientemente fallecida, debía ser cuidada por su abuela, también tuberculosa. Calmette creyó su deber ensayar esta vacuna, tan favorable en diversos animales e hizo absorber al niño $6 \mathrm{mg}$ de $\mathrm{BCG}$ en tres dosis, por vía oral. Aunque permaneció dos años en medio de sus parientes tuberculizados, no se produjo ningún accidente ni contrajo la enfermedad. Otras vacunaciones también tuvieron buenos resultados. Experiencias de laboratorio tanto en Francia, como en otros países de Europa y de América, demostraban que el BCG no adquiría virulencia en el organismo ${ }^{7}$.

En Chile, la década del 30 se inicia "con activa polémica sobre la vacunación BCG, recientemente introducida en el país, en la que participó el propio descubridor ${ }^{8}$. El profesor Aníbal Ariztía hizo notar que algunas observaciones, aunque aisladas, nacionales y extranjeras, revelaban que la vacuna BCG en esos casos no había evitado la infección y a veces podría atribuírsele el haberla provocado. Piensa, junto con Kraus, que "la vacuna no puede todavía ser entregada al médico práctico como arma de la lucha antituberculosa, mientras no se aclaren algunos puntos relativos al destino de los bacilos inoculados, duración de la protección, etc" .

La vacuna provenía de cepas proporcionadas por Calmette al doctor Oscar Fontecilla y preparada en el laboratorio del doctor Marco A. Sepúlveda.

Uno de los niños referidos por Ariztía falleció. Se comprobó lesiones en los ganglios paratraqueales y bronquiales. Las inoculaciones demostraron en cuyes la presencia de lesiones tuberculosas ${ }^{9}$. Por otra parte, existía en Santiago, una Comisión de control de la vacuna Calmette, la cual en vista de estos hechos y de otros producidos en Alemania con gran escándalo, pidió que se suspendiera momentáneamente la vacunación, en espera del esclarecimiento de los hechos, medida que acordó la Junta de Beneficencia de Santiago, el 30 de junio de 1930.

¿Qué había acontecido en Alemania? Con gran alarma y sorpresa, Calmette y Guerin supieron que numerosos niños vacunados (71 de 252) en Lübeck, desde diciembre de 1929 a abril de 1930, con vacuna preparada en el hospital de la ciudad, habían fallecido de tuberculosis. La cepa que el Instituto Pasteur había enviado a fines de Julio de 1929 a Lübeck era la misma utilizada en París, Riga y México, sin que en estos últimos lugares se hubiere producido casos fatales. Se comprobaron dos faltas graves: 1) que las cepas del Instituto Pasteur no habían sido resembradas en medios con bilis, tal como era la recomendación de Calmette, y 2) que la preparación de la vacuna se había hecho en un local donde se guardaban cepas de bacilos virulentos, los que se encontraron en las emulsiones vaccinales ingeridas por los niños, no adoptándose medidas para no confundirlas. Se demostró que las cepas de BCG no se habían hecho virulentas. Por estos motivos, el doctor Deycke, quien había preparado la vacuna en Lübeck, fue condenado a prisión por dos años ${ }^{7}$.

En Chile, se produjeron grandes discusiones en el seno de la Sociedad Médica de Santiago, sobre el problema de la vacunación BCG, con defensores y detractores irreductibles.

Finalmente, los accidentes no volvieron a repetirse. En 1938, el doctor Víctor Sierra S, en el Dispensario del Hospital San José de Santiago, inició la vacunación con BCG inyectable con controles previos y posteriores de test de tuberculina, constituyéndose sólo en la década del 50, en forma definitiva, como terapia de inmunización. Se estableció posteriormente que "el BCG no puede producir enfermedad progresiva en el hombre (salvo en las personas que tienen un sistema inmunitario muy deficiente), pero retiene la antigenicidad adecuada para lograr inmunización protectora contra la tuberculosis. 
"El azar sólo favorece a quien se encuentra preparado" -parece que lo dijo Pasteur y viendo su ejemplo, el de Jenner, el de Calmette y recordando a Fleming, podemos reiterar una vez más la sentencia francesa y reconocer toda la verdad que ella encierra: "regarder ce n" est pas voir".

\section{Bibliografía}

1.- Gajardo Tobar R. Las enfermedades de los aborígenes y el cataclismo que siguió a la Conquista. Rev Méd Chile 1979; 107: 182

2.- Edwards A, Yercovic L, Santamaría J. La tuberculosis y el Hospital San José de Santiago. Rev Méd Chile 1983; 111: 315.

3.- Koch R. Die Atiologie der Tuberkulose. Ber Klin Woch 1882; 19: 221.

4.- Pivet H. Notas históricas: Bacteriología de la Tuberculosis. Rev Méd Chile 1983; 111: 987.
5.- Laval M E. Iniciación de los estudios de Medicina en el siglo XVIII en Chile. Colegio Médico 1953; 5: 34.

6.- Laval R E. Conferencia sobre el Doctor Roberto Del Río. Hospital Roberto Del Río, 16 de marzo de 1989 (inédito).

7.- Laval M E. BCO. Apuntes para la historia de la Medicina (inédito).

8.- Medina L E. Contribución a la historia de la Medicina Chilena: 1930-1982. Rev Méd Chile 1983; 111: 368

9.- Ariztía A. Observaciones clínicas sobre cuatro niños vacunados con BCG y afectos de tuberculosis pulmonar Rev Méd Chile 1929; 57: 912.

10.- Ariztía A. La suspensión de ensayos de vacunación Calmette en Chile. Rev Méd Chile 1930; 58: 786,

11.- Wollman E. Estado actual de la vacunación con el BCG. Rev Méd Chile 1930; 58: 668.

12.- Organización Panamericana de la Salud: Control de la tuberculosis. Vacunación con BCO. 1987; Cáp. 2.

13.- Discusión sobre la vacunación BCO. Boletín de la Sociedad Médica de Santiago. Rev Méd Chile 1930; 58: 978. 